\title{
Effect of Object Position in Cone Beam Computed Tomography Field of View for Detection of Root Fractures in Teeth with Intra-Canal Posts
}

\author{
Solmaz Valizadeh, ${ }^{1}$ Zahra Vasegh, ${ }^{1, *}$ Samin Rezapanah, ${ }^{1}$ Yaser Safi, and Mohamad Javad \\ Khaeazifard ${ }^{2}$
}

${ }^{1}$ Department of Oral and Maxillofacial Radiology, School of Dentistry, Shahid Beheshti University of Medical Sciences, Tehran, Iran

${ }^{2}$ Dental Research Institute, Tehran University of Medical Sciences, Tehran, Iran

${ }^{*}$ Corresponding author: Zahra Vasegh, Department of Oral and Maxillofacial Radiology, School of Dentistry, Shahid Beheshti University of Medical Sciences, Tehran, Iran. Tel: +982188773550, Fax:+98-2188773550, E-mail:vaseghz@yahoo.com

Received 2014 November 11; Revised 2015 July 13; Accepted 2015 August 15.

\begin{abstract}
Background: Vertical root fracture (VRF) is a common problem in endodontically treated teeth. Due to its poor prognosis, a reliable technique must be used to make an accurate diagnosis. Cone beam computed tomography (CBCT) has been recently introduced for maxillofacial imaging. Despite the high diagnostic value of this method, metal artifacts resulting from intra-canal posts still make the detection of VRFs challenging.

Objectives: This study aimed to assess the effect of object position in the field of view (FOV) of CBCT on detection of VRFs in teeth with intra-canal posts.

Materials and Methods: The crowns of 60 extracted premolar teeth were cut at the level of cementoenamel junction (CEJ). Root canals were filled with gutta-percha and filling of the coronal $2 / 3$ of the root canals was subsequently removed to fabricate intra-canal cast posts. The teeth were randomly divided into two groups of 30. Fracture was induced in group one using an Instron machine. Group two was considered as the control group with no fracture. All teeth were then randomly positioned and scanned in five different positions starting at the center of the FOV as well as right, left anterior and posterior relative to the center (3, 9, 12, and 6 O'clock) via the New Tom VGI CBCT unit. Two observers evaluated images for VRFs. Sensitivity and specificity of fracture diagnosis in each position was calculated in comparison with the gold standard. Wilcoxon test was used for data analysis.

Results: Considering deterministic and probabilistic diagnostic parameters, probabilistic sensitivity was similar in all positions; but probabilistic specificity of the center position (65.1\%) was significantly higher than that of 6 and 12 O'clock positions. Considering the deterministic diagnostic parameters, the overall sensitivity and specificity values decreased in all positions in FOV, but sensitivity of the center position of FOV was significantly higher than that of other positions; specificity was significantly higher at the 3 O'clock position (58.5\%).

Conclusion: Concerning the positions in FOV, the center position is suitable for detection of VRF in teeth with intra-canal posts due to significantly higher sensitivity at this position. The 3 O'clock position would be suitable for assessment of intact teeth without fractures due to significantly higher specificity at this position.
\end{abstract}

Keywords: Tooth Fracture, Cone-Beam Computed Tomography, Post and Core Technique, Position

\section{Background}

Vertical root fracture (VRF) is among the most common causes of endodontic failures (1). Detection of VRF is often challenging (2). Over time, VRF may cause separation of broken pieces and compromise prognosis. VRF is the third most common cause of tooth extraction (3). Thus, its detection before endodontic treatment or tooth restoration is necessary. The currently used conventional techniques for detection of VRFs include bite test, direct observation and examination using a surgical microscope; however, these methods have some limitations (4-7).

VRF can be detected radiographically only when the fracture line is parallel to the path of beams (8). Otherwise, the fracture cannot be observed on a two-dimensional (2D) radiograph, particularly in early phases when the fracture line is in the form of a fine crack and the broken pieces are still attached. Superimposition of the adjacent structures is another factor limiting the sensitivity of conventional radiography for detection of VRFs. Recently, the efficacy of CBCT systems has been evaluated for detection of VRFs. According to the literature, such three-dimensional (3D) techniques have higher diagnostic value than conventional radiography for detection of VRFs (9-13). CBCT has favorable

Copyright ( ) 2015, Tehran University of Medical Sciences and Iranian Society of Radiology. This is an open-access article distributed under the terms of the Creative Commons Attribution-NonCommercial 4.0 International License (http://creativecommons.org/licenses/by-nc/4.0/) which permits copy and redistribute the material just in noncommercial usages, provided the original work is properly cited. 
Valizadeh S et al.

properties including high resolution, quick scanning time, lower cost and significantly decreased radiation exposure dose compared to standard CT. Studies demonstrated that CBCT has superior diagnostic accuracy for detection of VRFs in comparison with other imaging modalities in teeth without root canal filling or intracanal post (14-18).

Restorative treatment of endodontically treated teeth often includes placement of an intra-canal post. Metal objects including intra-canal postscan cause artifacts in the form of "streak lines" on CBCT images mimicking root fracture. Metal artifacts can compromise the diagnostic value of images. Functionally, confining the imaging to the FOV significantly decreases patient radiation dose and metal artifacts. Location of an object in the FOV can also affect the quality and accuracy of images $(19,20)$ as the artifacts, scattering radiation and noise in CBCT systems are not homogenously spread entirely across FOVs (21).

The effects of size of FOV, resolution of CBCT system and scanning parameters on metal artifacts and diagnostic accuracy of CBCT for detection of VRFs in teeth with and without intra-canal posts have been evaluated in previous studies (19, 22-24). However, the effect of object position in the FOV has not yet been investigated in this regard.

\section{Objectives}

Thus, in this study, we changed the position of fractured teeth with intra-canal posts within the FOV and assessed them at five different positions at the center of the FOV, left, right, anterior and posterior via CBCT for detection of VRFs in teeth.

\section{Materials and Methods}

This in-vitro study was conducted on 60 human premolar teeth with no root fracture or root caries. The samples were selected irrespective of age and sex from patients in whom teeth were extracted for orthodontic treatment. Extracted teeth were cleaned from debris and soft tissue residues and the teeth crowns were cut at the level of the cementoenamel junction (CEJ) using a micro-motor and a metal disc. All teeth then underwent root canal therapy. The coronal part of the root canal was pre-flared using \#2 and \#3 Gates Glidden drills (Dentsply Maillefer, Ballaigues, Switzerland). Root canals were prepared using \#15 - \#50 files (Dentsply Maillefer, Ballaigues, Switzerland) and intra-canal debris was removed via irrigation with $1.25 \%$ sodium hypochlorite solution. After preparation, root canals were filled with gutta-percha (AriaDent, Tehran, Iran) and sealer (Dentsply Detrey, Weybridge, UK). After one week, post space was prepared by removing gutta-percha from the coronal 2/3 of the root canal using \#2 and \#3 peeso reamers (Dentsply Maillefer, Ballaigues, Switzerland). Periapical radiographs were obtained to ensure accurate post space preparation. Post-pattern was prepared for all teeth using Duralay acrylic resin (Figure 1) (AriaDent, Tehran, Iran). Cast posts were fabricated of nickel and chrome. Each post was then tried in the root canal, modified for perfect fit and placed in the canal. Due to the risk of cement flow into the fracture line, posts were not cemented to the root canals. Each tooth was covered with a layer of green wax (Dentsply DeTrey, Weybridge, UK) with approximately $1 \mathrm{~mm}$ thickness and separately mounted in an acrylic block. Next, 30 of 60 specimens were randomly selected for induction of VRF. The prefabricated brass dowel of the Instron machine was placed in the root canals to enhance fracture induction. Root fractures were induced using a universal testing machine (ZwickRoell Z020, Germany). Force was gradually increased until the compressive force of the pin induced a fracture and the sound was heard. Upon fracture, the force was discontinued according to the diagram displayed on the system monitor (Figure 2).

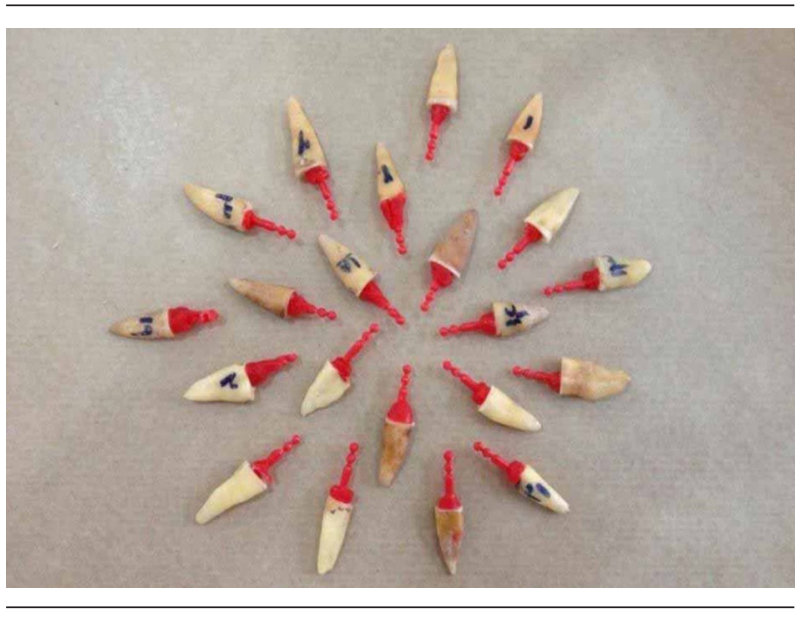

Figure 1. Post-pattern preparation for fabrication of intra-canal metal posts

Completely crushed teeth were excluded from the study. Fracture was not induced in the remaining 30 teeth as controls. During the study, all teeth were stored in a humid environment and were only removed from this environment for post fabrication, root fracture induction and radiography.

\subsection{Image Scanning}

In this study, 60 teeth (30 with VRFs and 30 without VRFs) were divided into 12 groups each containing five teeth and a total of 60 scans were taken. Each scan from the five teeth contained both fractured and intact teeth and their location was changed and assessed at all five locations (central, 6 O'clock position: the most posterior part of the FOV, 12 O'clock: the most anterior part of the FOV, 3 O'clock: the right most part of the FOV and 9 O'clock position: the left most part of the FOV.

Indeed in the selected FOV, samples were located at five different positions starting at the center of FOV and (left, right, anterior, posterior) relative to the center in $\mathrm{x}(\mathrm{X})$ and $y(Y)$ axis of the FOV (Figure 3) (21). 

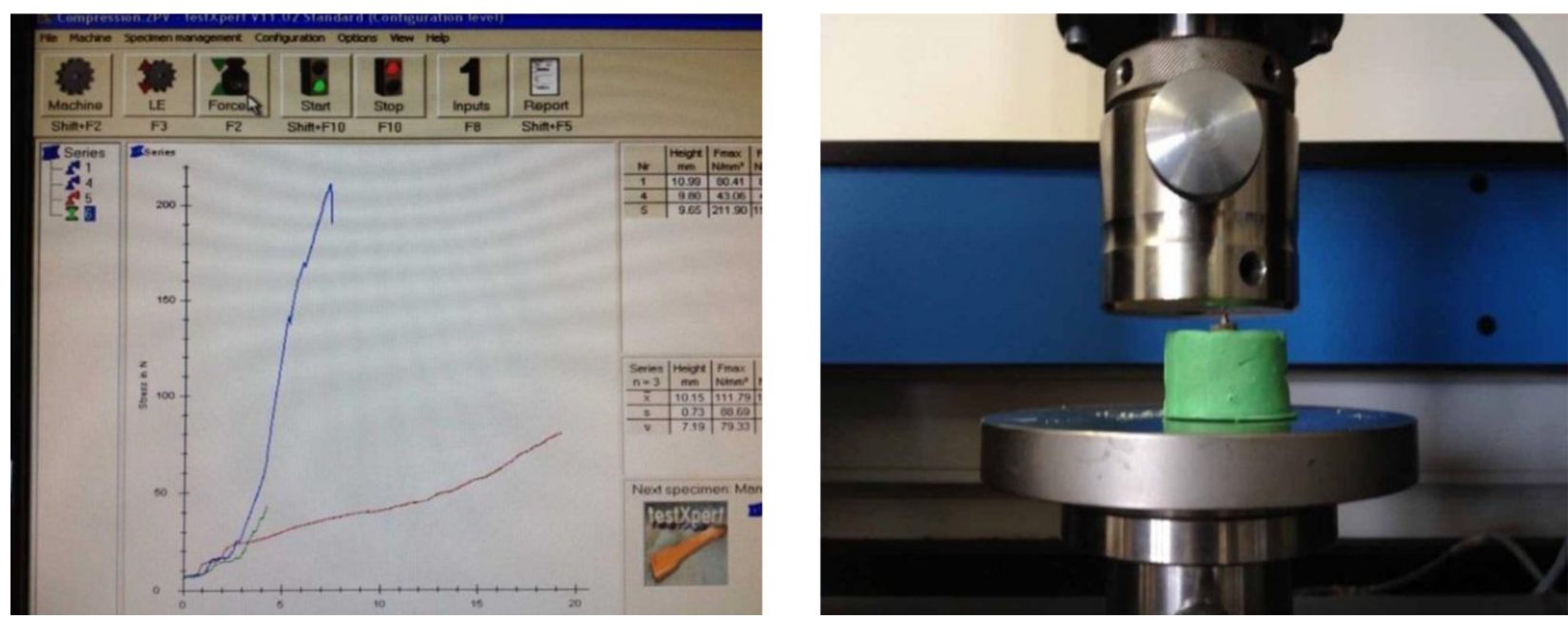

Figure 2. Upon hearing the fracture sound, load application was discontinued as displayed on the system monitor

Teeth were placed in a fine plastic cylinder containing water to simulate soft tissue with $13 \mathrm{~mm}$ diameter (19, 21, 25). The cylinder was placed on the chin rest of the New Tom VGI CBCT unit (Quantitative Radiology, Verona, Italy). CBCT scans were obtained using $15 \times 15 \mathrm{~cm}$ FOV, 0.2 $\mathrm{mm}$ voxel size (standard protocol), $110 \mathrm{KVP}$ and a Miliampere (MA) automatically adjusted for each specimen.

\subsection{Data Collection}

Two oral and maxillofacial radiologists blinded to the group allocation of teeth evaluated CBCT scans for VRFs. Presence of radiolucent lines in tooth root structure in cross sectional images of different planes considered as root fracture by the observers. The radiolucent lines extended out of the tooth structure were most compatible with intra-canal post artifacts. No time limitation was set for observation of images. CBCT scans were evaluated in axial, coronal and sagittal planes. The observers were allowed to enhance the image quality using all the available enhancement filters, magnification, contrast and brightness. Both observers first viewed axial and then coronal and sagittal planes similar to the study by Hassan et al. (Figure 4) (26). The observers recorded their observation from 1 to 5 using the following scale (27):
1. Definite fracture (Group 1),
2. Probable fracture (Group 2),
3. Definitely no fracture (Group 3),
4. Probably no fracture (Group 4),
5. Undetectable.

According to previous studies, confirmation of the presence (group with fracture) and absence (control group) of fracture lines in root structure was essential, although these fractures were induced using testing machine. Methylene blue has been introduced as one of the best ways for this confirmation (as Gold standard) $(26,28,29)$. Therefore, specimens were removed from acrylic blocks and stained with Methylene blue and evaluated by transillumination. In cases with VRF, Methylene blue penetrated into the fracture line and visualized on the tooth surface as dark blue line.

\subsection{Statistical Analysis}

Data were collected and entered SPSS version 20.0 software (IBM Corp. U.S.A).Wilcoxon test was used for data analysis. The inter-observer agreement was measured using weighted Kappa.

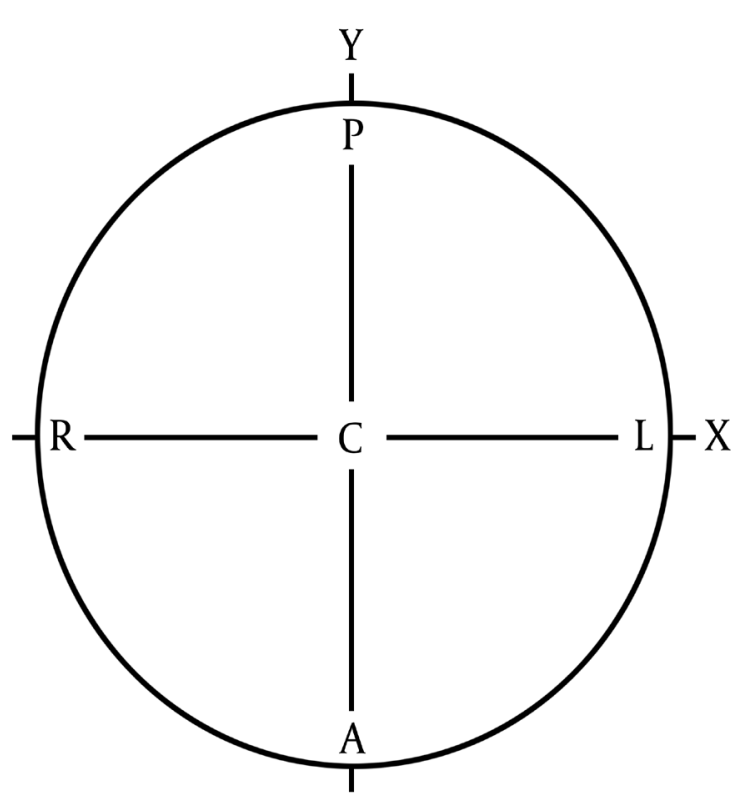

Figure 3. Different sample positions in each FOV. center $(C)$, right $(R)$, left $(\mathrm{L})$, anterior $(\mathrm{A})$ and posterior $(\mathrm{P})$ locations relative to the $\mathrm{x}$ axis $(\mathrm{X})$ and $\mathrm{y}$ axis (Y) of the FOV. 

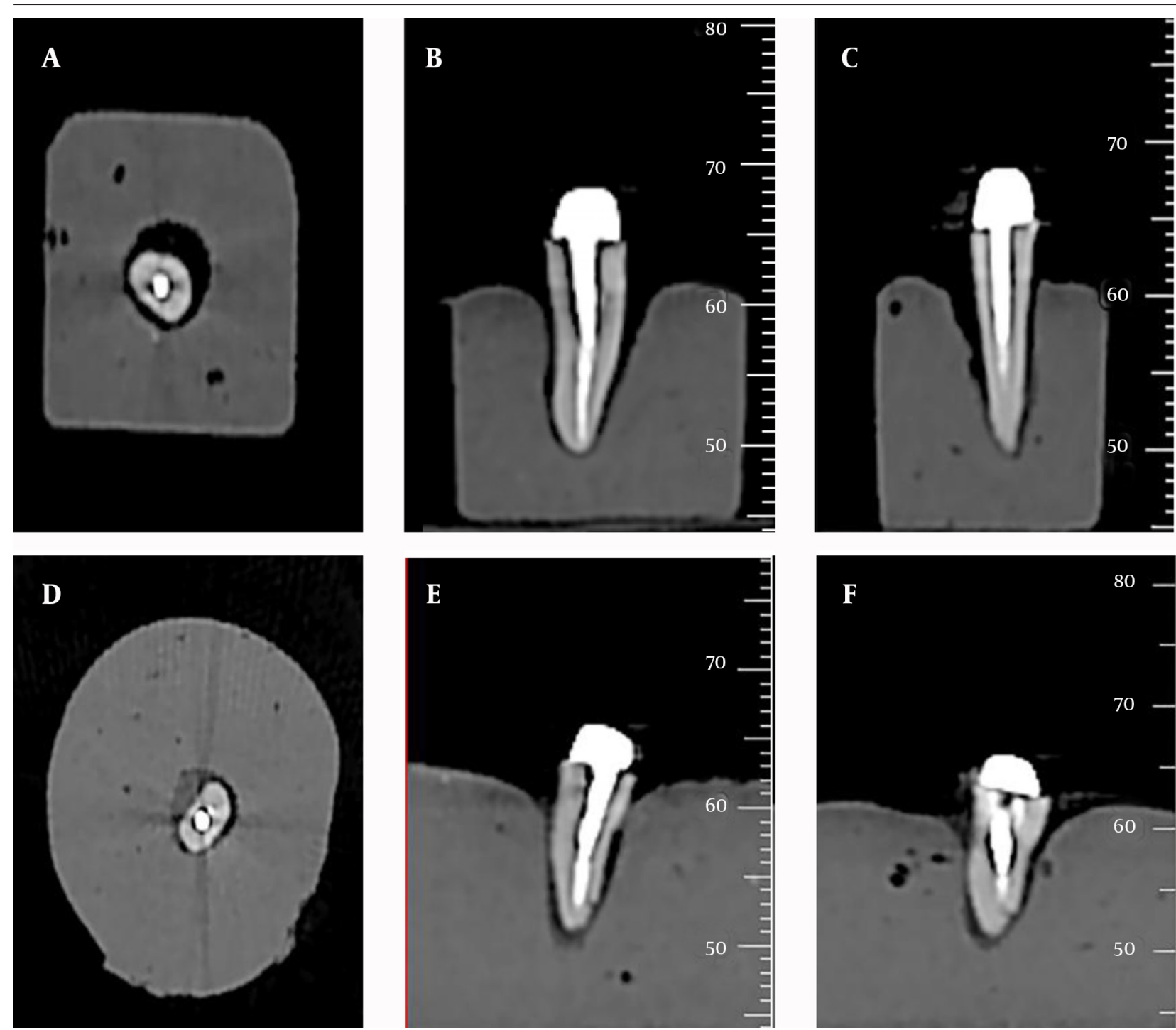

Figure 4. CBCT scans of teeth without fracture (A: axial, B: coronal, C: sagittal) and with fracture (D: axial, E: coronal, F: sagittal).

\section{Results}

In our study, considering the scale used for reporting the observers' diagnosis, the results were described as deterministic and probabilistic sensitivity and specificity. Deterministic sensitivity and specificity describe observers' clinical opinion regarding definite presence or absence of VRFs, which were calculated as follows:

Deterministic sensitivity: proportion of cases in which VRFs were diagnosed definitely (Group 1) to all cases that really have fractures.

Deterministic specificity: proportion of cases in which intact teeth without fractures were diagnosed definitely (Group3) to all cases that are really intact.

Whereas, probabilistic sensitivity and specificity also included their opinion regarding the possibility of presence or absence of VRFs. They were calculated as below: probabilistic sensitivity: proportion of cases in which VRFs were diagnosed definitely and probably ( Groups 1, 2) to all cases that really have fractures.

Probabilistic specificity: proportion of cases in which intact teeth without fractures were diagnosed definitely and probably (Groups 3, 4) to all cases that are really intact.

In undetectable cases, the observers could not define presence or absences of fracture lines (definitely or probably), but these cases were not excluded from the analysis. They were considered in all cases that really had fracture or not according to the gold standard.

Comparison of different positions of teeth in CBCT FOV for sensitivity and specificity were as follows:

The highest deterministic sensitivity was obtained at the center of FOV followed by 12, 9, 6, and 3 O'clock posi- 
tions, respectively. No statistically significant difference was found between 3 and 6 O'clock or 9 and 12 O'clock positions in this respect.

The highest probabilistic sensitivity was seen at the 9 O'clock position followed by 6 and 12 O'clock, center and 3 O'clock positions, respectively. No significant difference was found in probabilistic sensitivity between 6 and 9 O'clock and the center positions, but probabilistic sensitivity at the 3 O'clock position was significantly lower than that in other positions.

The 3 O'clock position had the highest deterministic specificity, which showed significant differences with that in other positions. The center and 6,12 and, 9 O'clock positions ranked next, respectively. Deterministic specificity was not significantly different at 6 and 12 O'clock and the center positions.

Probabilistic specificity was significantly higher at the center compared to other positions, followed by 3 , 6, 9, and 12 O'clock positions, respectively. Probabilistic specificity was significantly different at the center and 12 O'clock positions but no significant difference was found in this respect between the center and 12 O'clock positions. Probabilistic specificity at 6 and 9 O'clock positions was not significantly different from that in other positions.

Deterministic sensitivity and specificity values were low in all positions; however, sensitivity at the center position was significantly higher than that in other positions. The specificity was the highest at the 3 O'clock position.

Probabilistic sensitivity was the same in all positions; but probabilistic specificity was significantly higher at the center position compared to 6 and 12 O'clock positions.

Tables 1 and 2 summarize the obtained data regarding detection of VRFs by observers in different positions of teeth within FOV of CBCT unit. Means and confidence intervals evaluated for diagnostic values of two observers are shown in Table 3.

\begin{tabular}{|c|c|c|c|c|c|}
\hline Position & Observer & $\begin{array}{c}\text { Deterministic } \\
\text { Sensitivity }\end{array}$ & $\begin{array}{c}\text { Probabilistic } \\
\text { Sensitivity }\end{array}$ & $\begin{array}{c}\text { Deterministic } \\
\text { Specificity }\end{array}$ & $\begin{array}{c}\text { Probabilistic } \\
\text { Specificity }\end{array}$ \\
\hline \multicolumn{6}{|l|}{3 O'clock } \\
\hline & First observer & 3.3 & 20.0 & 53.0 & 46.7 \\
\hline & Second observer & 6.0 & 36.7 & 50.0 & 73.3 \\
\hline \multicolumn{6}{|l|}{6 O'clock } \\
\hline & First observer & 7.1 & 28.5 & 12.5 & 50.0 \\
\hline & Second observer & 0 & 46.4 & 37.5 & 59.4 \\
\hline \multicolumn{6}{|l|}{9 O'clock } \\
\hline & First observer & 6.7 & 33.4 & 16.7 & 63.4 \\
\hline & Second observer & 13.3 & 43.3 & 40.0 & 43.3 \\
\hline \multicolumn{6}{|c|}{12 O'clock } \\
\hline & First observer & 13.3 & 36.6 & 16.7 & 60.0 \\
\hline & Second observer & 10.0 & 36.7 & 30.0 & 40.0 \\
\hline \multicolumn{6}{|l|}{ Center } \\
\hline & First observer & 13.3 & 33.3 & 26.7 & 73.4 \\
\hline & Second observer & 16.7 & 33.3 & 36.7 & 56.7 \\
\hline
\end{tabular}

Table 2. Mean and Merged \%95 Confidence Interval of Sensitivity and Specificity Values of Two Observers for Detection of Vertical Root Fracture (\%)

\begin{tabular}{|c|c|c|c|c|}
\hline Position & Deterministic Sensitivity & Probabilistic Sensitivity & Deterministic Specificity & Probabilistic Specificity \\
\hline 3 O'clock & $5(2.6-7.4)$ & $28.2(22.72-33.68)$ & $58.5(50.6-66.4)$ & $63.4(54.72-72.08)$ \\
\hline 6 O’clock & $3.6(1.2-6)$ & $37.5(32-42.98)$ & $25.0(17.1-27.9)$ & $54.7(46.02-63.38)$ \\
\hline 9 O'clock & $10.0(7.6-12.4)$ & $38.4(32.9-43.88)$ & $10.4(2.5-18.3)$ & $53.4(44.72-62.08)$ \\
\hline 12 O'clock & $11.7(9.3-14.1)$ & $36.7(31.2-42.18)$ & $23.9(15.5-31.3)$ & $50.0(41.32-58.68)$ \\
\hline Center & $15.0(12.6-17.4)$ & $33.4(27.92-38.88)$ & $31.7(23.8-39.6)$ & $65.1(56.42-73.78)$ \\
\hline
\end{tabular}


Valizadeh S et al.

\begin{tabular}{|c|c|c|c|c|c|}
\hline Position & Observer & PPV & NPV & PLR & NLR \\
\hline \multicolumn{6}{|l|}{3 O'clock } \\
\hline & First Observer & 4.76 & 25.64 & 0.1 & 0.68 \\
\hline & Second Observer & 11.76 & 34.88 & 0.13 & 0.54 \\
\hline \multicolumn{6}{|l|}{6 O'clock } \\
\hline & First Observer & 10.34 & 12.90 & 0.08 & 0.13 \\
\hline & Second Observer & 0 & 26.83 & 0 & 0.37 \\
\hline \multicolumn{6}{|l|}{9 O'clock } \\
\hline & First Observer & 7.4 & 15.15 & 0.08 & 0.20 \\
\hline & Second Observer & 18.18 & 31.58 & 0.22 & 0.46 \\
\hline \multicolumn{6}{|c|}{12 O'clock } \\
\hline & First Observer & 13.79 & 16.13 & 0.16 & 0.19 \\
\hline & Second Observer & 12.5 & 25.00 & 0.14 & 0.33 \\
\hline \multicolumn{6}{|l|}{ Center } \\
\hline & First Observer & 15.38 & 23.52 & 0.18 & 0.32 \\
\hline & Second Observer & 20.83 & 30.56 & 0.26 & 0.44 \\
\hline
\end{tabular}

a Abbreviations: NLR, negative likelihood ratio; NPV, negative predictive value; PPV, positive predictive value; PLR, positive likelihood ratio.

\section{Discussion}

Teeth with VRFs often have a poor prognosis and extraction is usually the treatment of choice for such cases. Thus, early accurate diagnosis is critical (28). Since the American food and drug administration (FDA) approval of CBCT in 2000, the efficacy and accuracy of this system for detection of VRFs have been the subject of many investigations. Due to high diagnostic accuracy and low radiation dose in comparison with computed tomography, CBCT has been introduced as an excellent alternative to periapical conventional and digital radiography for detection of VRFs under in vitro and in vivo conditions (14, $30,31)$ and various articles confirmed this superiority ( 25 , 31,32 ), but these investigations were all in teeth without any root canal filling or intra-canal posts.

Though, about $90 \%$ of teeth with VRFs have root canal filling materials and approximately $61.7 \%$ of them have intra-canal posts (22). These materials cause streak-like artifacts in CBCT images and significantly decrease the diagnostic accuracy, since dark streaks may be mistaken by fractures and light streaks may mask actual fracture lines and account for cases of false positive and false negative results (19). The magnitude of reduction in the diagnostic accuracy of imaging systems due to root canal filling materials and intra-canal post artifacts has been variable. According to a study by Costa et al. (19), presence of a metallic post significantly reduces the specificity and sensitivity of VRF detection.

Evidence shows that sensitivity and specificity values for detection of VRF by CBCT systems are influenced by the amount of artifacts and are dependent on the voxel size, FOV size, presence and type of intra-canal post, type of imaging system, variety of detectors, imaging slice thickness, VRF dimension, scanning parameters and etc. (19).

Artifacts, scattering radiation and noise in CBCT systems are not equally spread entirely across the FOVs (21). The current study was designed to assess the effect of changing object position within the field of view of CBCT on diagnostic parameters for VRF detection.

Voxel size of $0.2 \mathrm{~mm}$ was used in the current study. Melo et al. stated $0.2 \mathrm{~mm}$ voxel size as the most suitable protocol for this purpose due to low radiation dose and optimal diagnostic accuracy $(12,28)$.

In the current study, a large FOV was used because Costa et al. demonstrated that presence of intra-canal posts significantly decreased the diagnostic accuracy for detection of VRFs in small FOVs $(19,22)$.

Changing slice thickness has no significant effect on the amount of artifacts (23); therefore, a slice thickness of 1 $\mathrm{mm}$ was used in the current study. In a previous study, less metal artifacts, noise and contrast and higher image resolution were attained using five $\mathrm{CBCT}$ systems with flat panel detectors compared to systems using image intensifier tubes/CCD detectors (24). Therefore, flat panel detectors were used in the current study.

Despite these considerations, intra-canal post artifacts significantly influenced sensitivity and specificity of VRF detection in every position of FOV. Using nickel chromium posts may be one of the reasons. These posts produce high degree detectable artifacts. A previous study on the effect of intra-canal post material on the amount of artifacts reported that gold and silver alloys caused the most, 
Valizadeh S et al.

and carbon fiber posts the least artifacts (26).

Considering deterministic diagnostic parameters (clinical opinions regarding definite presence or absence of VRFs), the overall sensitivity and specificity values decreased in all positions of the FOV. These findings are similar to those of Costa et al. (19), indicating significant reduction of these values in presence of metallic posts.

Affording to FOV location, sensitivity of the center position of FOV was significantly higher than that of other positions and specificity was significantly higher at the 3 O'clock position (58.5\%). Regarding the highest sensitivity at the center position of the FOV in comparison with other FOV positions, it seems that masking the actual fracture line and simulation of fracture lines by lucent lines are minimal in this position. Considering the highest specificity at the 3 O'clock position of FOV, the probability of fracture line simulation by lucent streak artifacts is the lowest in this position.

Considering deterministic and probabilistic diagnostic parameters, probabilistic sensitivity was similar at all positions, but probabilistic specificity of the center position (65.1\%) was significantly higher than that of 6 and 12 O'clock positions.

In this study, the overall agreement among the observers was moderate (kappa $=0.548$ ), this is according to previous studies that showed weak to no agreement in evaluation of fractured teeth with intra-canal posts (19, $22,26)$, that is completely dependent on large amount of artifacts produced by metal posts and superimposed on roots structure. Apart from the amount of reduction in sensitivity and specificity of VRF detection which is quite inconstant in different studies, variations in different positions of the FOV may be explained by considerable artifacts, scattering radiation and noise in this type of CBCT system, which are not homogeneously spread throughout all FOV. This may also be explained by the lower applied KVP and $\mathrm{mA}$ resulting in greater scattering and noise in selected FOVs (23).

The possible effect of object location within CBCT FOV on gray values has also been investigated in previous studies, but no consensus reached in this regard $(33,34)$. A previous study on the effect of object location within the selected FOV in two CBCT systems (Accuitomo170 and NewTom 5G) on the gray value at an implant site reported fluctuations in gray values as a function of location of the object within FOV; this instability increased with the size of FOV. Increased noise level, scattering and artifacts specific to CBCT technology used may explain such inconsistency (35).

In another study, highly variable gray values were resulted from scans at the center and off-center of the FOV, especially when the objects were positioned off-center of the FOV(33).

Normally, these points can be valuable for clinical diagnosis of VRFs. In vitro nature of this study is the most important limitation in generalizing results in clinic. Thus, we suggest subsequent investigations to follow this study with an in vivo design (by placing teeth in dry mandibule) using various CBCT systems with different exposure parameters.

Presence of intra-canal metallic posts significantly reduced sensitivity and specificity of VRF diagnosis. Based on the results, the center position in the FOV is the most suitable one for accurate detection of VRFs in teeth with intra-canal posts due to significantly higher sensitivity in this position. The 3 O'clock position in the FOV is the most suitable one for accurate assessment of intact teeth due to significantly higher specificity in this position.

\section{Footnote}

Authors' Contributions:Study concept and design: Solmaz Valizadeh, Zahra vasegh, Samin Rezapanah, Yaser Safi. Acquisition of data: Solmaz Valizadeh, Zahra vasegh, Samin Rezapanah, Yaser Safi. Analysis and interpretation of data: Mohamad Javad Kharazi Mohamad Javad Khaeazifard, drafting of the manuscript: Solmaz Valizadeh, Zahra vasegh, Samin Rezapanah, Yaser Safi. Critical revision of the manuscript for important intellectual content: Solmaz Valizadeh, Zahra Vasegh. Statistical analysis: Mohamad Javad Khaeazifard. Study supervision: Solmaz Valizadeh and Zahra Vasegh.

\section{References}

1. Martins JNR, Canta JP, Coelho A, Baharestani M. Vertical root fracture diagnosis of crowned premolars with root canal treatment - Two case reports. Next Document Rev Port Estomatol Med Dent Cir Maxilofac. 2014;55(1):60-4. doi: 10.1016/j. rpemd.2013.11.002.

2. Zou X, Liu D, Yue L, Wu M. The ability of cone-beam computerized tomography to detect vertical root fractures in endodontically treated and nonendodontically treated teeth: a report of 3 cases. Oral Surg Oral Med Oral Pathol Oral Radiol Endod. 2011;111(6):797801. doi:10.1016/j.tripleo.2010.12.015. [PubMed: 21439864]

3. Khasnis SA, Kidiyoor KH, Patil AB, Kenganal SB. Vertical root fractures and their management. J Conserv Dent. 2014;17(2):103-10. doi:10.4103/0972-0707.128034. [PubMed: 24778502]

4. Shemesh H, van Soest G, Wu MK, Wesselink PR. Diagnosis of vertical root fractures with optical coherence tomography. J Endod. 2008;34(6):739-42. doi: 10.1016/j.joen.2008.03.013. [PubMed: 18498903]

5. Remya C, Indiresha HN, George JV, Dinesh K. Vertical root fractures: A review. Int J Contemp Dent Med Rev. 2015:1-4.

6. Paul RA, Tamse A, Rosenberg E. Cracked and broken teeth-definitions, differential diagnosis and treatment. Refuat Hapeh Vehashinayim (1993). 2007;24(2):7-12. [PubMed: 17696060]

7. Fisekcioglu E, Dolekoglu S, Ilguy M, Ersan N, Ilguy D. In Vitro Detection of Dental Root Fractures with Cone Beam Computed Tomography (CBCT). Iran J Radiol. 11(1):e25272 doi: 10.5812/iranjradiol.1148.

8. Ezzodini Ardakani F, Razavi SH, Tabrizizadeh M. Diagnostic value of cone-beam computed tomography and periapical radiography in detection of vertical root fracture. Iran Endod J. 2015;10(2):122-6. [PubMed: 25834597]

9. Youssefzadeh S, Gahleitner A, Dorffner R, Bernhart T, Kainberger FM. Dental vertical root fractures: value of CT in detection. Radiology. 1999;210(2):545-9. doi: 10.1148/radiology.210.2.r99ja20545. [PubMed: 10207442]

10. Nair MK, Nair UP, Grondahl HG, Webber RL. Accuracy of tuned aperture computed tomography in the diagnosis of radicular fractures in non-restored maxillary anterior teeth-an in vitro study. Dentomaxillofac Radiol. 2002;31(5):299-304. doi: 10.1038| 
sj.dmfr.4600712. [PubMed:12203128]

11. Hannig C, Dullin C, Hulsmann M, Heidrich G. Three-dimensional, non-destructive visualization of vertical root fractures using flat panel volume detector computer tomography: an ex vivo in vitro case report. Int Endod J. 2005;38(12):904-13. doi: 10.1111/j.13652591.2005.01033.x. [PubMed:16343118]

12. da Silveira PF, Vizzotto MB, Liedke GS, da Silveira HL, Montagner F, da Silveira HE. Detection of vertical root fractures by conventional radiographic examination and cone beam computed tomography - an in vitro analysis. Dent Traumatol. 2013;29(1):41-6. doi:10.111//j.1600-9657.2012.01126.x. [PubMed: 22413921]

13. Miyagaki DC, Marion J, Randi Ferraz CC. Diagnosis of vertical root fracture with cone-beam computerized tomography in endodontically treated teeth: three case reports. Iran Endod J. 2013;8(2):75-9. [PubMed: 23717335]

14. Mora MA, Mol A, Tyndall DA, Rivera EM. In vitro assessment of local computed tomography for the detection of longitudinal tooth fractures. Oral Surg Oral Med Oral Pathol Oral Radiol Endod. 2007;103(6):825-9. doi: 10.1016/j.tripleo.2006.09.009. [PubMed: 17188531]

15. Kwong JC, Palomo JM, Landers MA, Figueroa A, Hans MG. Image quality produced by different cone-beam computed tomography settings. Am J Orthod Dentofacial Orthop. 2008;133(2):317-27. doi:10.1016/j.ajodo.2007.02.053. [PubMed:18249300]

16. Jakobson SJ, Westphalen VP, Silva Neto UX, Fariniuk LF, Schroeder AG, Carneiro E. The influence of metallic posts in the detection of vertical root fractures using different imaging examinations. Dentomaxillofac Radiol. 2014;43(1):20130287. doi: 10.1259/ dmfr.20130287. [PubMed: 24191261]

17. Moudi E, Haghanifar S, Madani Z, Alhavaz A, Bijani A, Bagheri M. Assessment of vertical root fracture using cone-beam computed tomography. Imaging Sci Dent. 2014;44(1):37-41. doi: 10.5624/ isd.2014.44.1.37. [PubMed: 24701457]

18. Baek HJ, Kim DW, Ryu JH, Lee YJ. Identification of Nasal Bone Fractures on Conventional Radiography and Facial CT: Comparison of the Diagnostic Accuracy in Different Imaging Modalities and Analysis of Interobserver Reliability. Iran J Radiol. 2013;10(3):140147. doi:10.5812/iranjradiol.6353. [PubMed:24348599]

19. Costa FF, Gaia BF, Umetsubo OS, Cavalcanti MG. Detection of horizontal root fracture with small-volume cone-beam computed tomography in the presence and absence of intracanal metallic post. J Endod. 2011;37(10):1456-9. doi: 10.1016/j.joen.2011.05.040. [PubMed: 21924202]

20. White SC, Pharoah MJ. Oral radiology: Principles and interpretation. 8th ed. Torento, Canada: Mosby; 2014. pp.185-99.

21. Parsa A, Ibrahim N, Hassan B, van der Stelt P, Wismeijer D. Influence of object location in cone beam computed tomography (NewTom 5G and 3D Accuitomo 170) on gray value measurements at an implant site. Oral Radiology. 2014;30(2):153-9.

22. Costa FF, Gaia BF, Umetsubo OS, Pinheiro LR, Tortamano IP, Cavalcanti MG. Use of large-volume cone-beam computed tomography in identification and localization of horizontal root fracture in the presence and absence of intracanal metallic post. $J$ Endod. 2012;38(6):856-9. doi: 10.1016/j.joen.2012.03.011. [PubMed: 22595127]
23. Estrela C, Bueno MR, Silva JA, Porto OCL, Leles CR, Azevedo BC. Ef fect of intracanal posts on dimensions of cone beam computed tomography images of endodontically treated teeth. Dental Press Endodontics. 2011;1(1):28-36. doi:10.14436/2178-3713.1.1.028-036.oar.

24. Hassan B, Metska ME, Ozok AR, van der Stelt P, Wesselink PR. Comparison of five cone beam computed tomography systems for the detection of vertical root fractures. J Endod. 2010;36(1):126-9. doi:10.1016/j.joen.2009.09.013. [PubMed: 20003950]

25. Katsumata A, Hirukawa A, Noujeim M, Okumura S, Naitoh M, Fujishita M, et al. Image artifact in dental cone-beam CT. Oral Surg Oral Med Oral Pathol Oral Radiol Endod. 2006;101(5):652-7. doi: 10.1016/j.tripleo.2005.07.027. [PubMed:16632279]

26. Hassan B, Metska ME, Ozok AR, van der Stelt P, Wesselink PR. Detection of vertical root fractures in endodontically treated teeth by a cone beam computed tomography scan. J Endod. 2009;35(5):719-22. doi: 10.1016/j.joen.2009.01.022. [PubMed: 19410091]

27. Kamburoglu K, Murat S, Pehlivan SY. The effects of digital image enhancement on the detection of vertical root fracture. Dent Traumatol. 2010;26(1):47-51. doi: 10.1111/j.1600-9657.2009.00841.x. [PubMed: 20089061]

28. Melo SL, Bortoluzzi EA, Abreu MJ, Correa LR, Correa M. Diagnostic ability of a cone-beam computed tomography scan to assess longitudinal root fractures in prosthetically treated teeth. J Endod. 2010;36(11):1879-82. doi: 10.1016/j.joen.2010.08.025. [PubMed: 20951305]

29. Ghorbanzadeh A, Aminifar S, Shadan L, Ghanati H. Evaluation of three methods in the diagnosis of dentin cracks caused by apical resection. J Dent (Tehran). 2013;10(2):175-85. [PubMed: 23724218]

30. Bornstein MM, Wolner-Hanssen AB, Sendi P, von Arx T. Comparison of intraoral radiography and limited cone beam computed tomography for the assessment of root-fractured permanent teeth. Dent Traumatol. 2009;25(6):571-7. doi: 10.1111/j.1600-9657.2009.00833.x. [PubMed:19843131]

31. Valiozadeh S, Khosravi M, Azizi Z. Diagnostic accuracy of conventional, digital and Cone Beam CT in vertical root fracture detection. Iran Endod J. 2011;6(1):15-20.

32. Bernardes RA, de Moraes IG, Hungaro Duarte MA, Azevedo BC de Azevedo JR, Bramante CM. Use of cone-beam volumetric tomography in the diagnosis of root fractures. Oral Surg Oral Med Oral Pathol Oral Radiol Endod. 2009;108(2):270-7. doi: 10.1016/j.tripleo.2009.01.017. [PubMed: 19272806]

33. Nackaerts O, Maes F, Yan H, Couto Souza P, Pauwels R, Jacobs R. Analysis of intensity variability in multislice and cone beam computed tomography. Clin Oral Implants Res. 2011;22(8):873-9. doi:10.111//j.1600-0501.2010.02076.x. [PubMed:21244502]

34. Lagravere MO, Carey J, Ben-Zvi M, Packota GV, Major PW. Effect of object location on the density measurement and Hounsfield conversion in a NewTom $3 G$ cone beam computed tomography unit. Dentomaxillofac Radiol. 2008;37(6):305-8. doi: 10.1259/ dmfr/65993482. [PubMed:18757714]

35. Maes F, Collignon A, Vandermeulen D, Marchal G, Suetens P. Multimodality image registration by maximization of mutual information. IEEE Trans Med Imaging. 1997;16(2):187-98. doi: 10.1109/42.563664. [PubMed: 9101328] 